\title{
Conservation Tillage Affects Species Composition But Not Species Diversity: A Comparative Study in Northern Italy
}

\author{
Francesco Boscutti • Maurizia Sigura • \\ Nadia Gambon · Corrado Lagazio • \\ Bertil O. Krüsi · Pierluigi Bonfanti
}

Received: 24 December 2013/Accepted: 3 November 2014/Published online: 13 November 2014

(C) Springer Science+Business Media New York 2014

\begin{abstract}
Conservation tillage (CT) is widely considered to be a practice aimed at preserving several ecosystem functions. In the literature, however, there seems to be no clear pattern with regard to its benefits on species diversity and species composition. In Northern Italy, we compared species composition and diversity of both vascular plants and Carabids under two contrasting tillage systems, i.e., CT and conventional tillage, respectively. We hypothesized a significant positive impact of CT on both species diversity and composition. We also considered the potential influence of crop type. The tillage systems were studied under open field conditions with three types of annual crops (i.e., maize, soybean, and winter cereals), using a split-plot design on pairs of adjacent fields. Linear mixed models were applied to test tillage system, crop, and interaction effects on diversity indices. Plant and Carabids communities were analyzed by multivariate methods (CCA). On the whole, 136 plant and 51 carabid taxa were recorded. The two tillage systems studied did not differ in floristic or carabid diversity. Species composition, by contrast, proved to be characteristic for each combination of tillage system and crop type. In particular, CT fields were characterized by nutrient demanding weeds and the associated Carabids.
\end{abstract}

F. Boscutti $(\bowtie) \cdot$ M. Sigura · N. Gambon · P. Bonfanti Department of Agriculture and Environmental Sciences, University of Udine, Via delle Scienze 208, 33100 Udine, Italy e-mail: francesco.boscutti@uniud.it

F. Boscutti · B. O. Krüsi

Zurich University of Applied Science ZHAW, Schloss, 8820 Wädenswil, Switzerland

\section{Lagazio}

Department of Economy, University of Genova, Via Vivaldi 5, 16126 Genoa, Italy
The differences were especially pronounced in fields with winter cereals. The same was true for the flora and Carabids along the field boundaries. For studying the effects of CT practices on the sustainability of agro-ecosystems, therefore, the focus should be on species composition rather than on diversity measures.

Keywords Agro-ecosystem sustainability - Biodiversity assessment $\cdot$ Soil conservation farming $\cdot$ Biocoenosis characterization

\section{Introduction}

Biodiversity affects renewal processes in the ecological services of agro-ecosystems and is, therefore, closely linked to both their productivity and sustainability. When biodiversity and the associated services are lost in agroecosystems, the costs may be significant (Altieri and Nicholls 2004). In agro-ecosystem, two components contribute to biodiversity. First, there is the planned diversity, encompassing the crops and livestock introduced and maintained by the farmer. Second there is the so-called associated biodiversity, provided by the plants and animals that are able to successfully colonize and survive in the agro-ecosystem (Vandermeer and Perfecto 1995). Both diversity components contribute to ecosystems services such as recycling of nutrients, hydrological regulation, pest control, etc. (Altieri and Nicholls 2004).

The internal regulation of ecological functions in agroecosystems greatly depends on the diversity of plants and animals. Several studies emphasize the crucial roles of (i) the species composition of the plant and animal communities and (ii) the functional traits of the species present to correctly asses the sustainability of agricultural 
ecosystems (House and Stinner 1983; Hald 1999; Albrecht 2003; Waldhardt et al. 2003; Dorado and López-Fando 2006; Gobbi and Fontaneto 2008).

In the context of sustainable agriculture, conservation tillage (CT) is considered a soil management practice aimed at preserving soil fertility and biodiversity and reducing negative impacts such as disruption of the soil's structure, erosion, and carbon loss during tillage (Mueller et al. 1981; Zentner et al. 2004, 2011; Conant et al. 2007). Non-inversion soil cultivation is the hallmark of $\mathrm{CT}$, in combination with adapted husbandry and crop techniques such as cover cropping, surface incorporation of crop residues, or crop rotation (Pisante 2007; Lahmar 2010). Holland (2004) and Trewavas (2004) reviewed many comparative studies from both the USA and Europe, and found CT to benefit both the environment and wildlife. The advantages observed include improved soil structure, greater organic matter content, reduced surface run-off, mitigated leaching of nutrients, and enhanced soil biodiversity.

The relationship between CT and biodiversity has been extensively studied, but from two different points of view: the productive one and the ecological one. The first aims at understanding how the tillage system affects weeds, pests, and diseases, in order to improve weed management and pest control programs. Studies showed weed control practices to be very similar on CT and conventional tillage (CoT) fields (Moyer et al. 1994) since CT had no major effect on weed biomass (Mas and Verdú 2003). Streit et al. (2002) showed how perennial weeds were preferentially found under no-tillage systems whereas annuals and broadleaved species were primarily associated with minimum tillage and CoT. The ecological approach showed how CT improves soil biodiversity and food supplies micro-, meso-, and macrofauna (Holland 2004; Field et al. 2007). In addition, Cole et al. (2005) investigated the effects of land cover and management intensity on ground beetles and spiders, and found management intensity to have a marked impact on both species numbers and composition.

Tillage has generally been shown to have a negative effect on ground beetles (Shearin et al. 2007). Several studies have shown that diversity of Carabids is greater in fields under minimum CT than in fields under CoT (French et al. 1998; Kromp 1999; Holland and Luff 2000; Hatten et al. 2007). Other authors, however, have found greater diversity of Carabids under CoT (Barney and Pass 1986; Carcamo 1995; Shrestha et al. 2002; Belaoussoff et al. 2003).

Further studies focused on effects of tillage system on biocoenoses species composition. A study conducted in Northern Italy by Zanin et al. (1997) evidenced the presence of a set of plant species associated with each tillage system tested. For Carabids beetles Holland and Luff (2000) also listed specific and different sets of species for ploughed crops and CT. Changes in agricultural practices entail modifications of environmental conditions and subsequently changes in the composition of the associated plant and animal communities.

Moreover, according to the literature, the type of crop and the associated agricultural practices have marked impact on both plant and Carabids communities (Booij 1994; Carcamo and Spence 1994; Andersson and Milberg 1998; Fried et al. 2008). Less is known, however, about the interactions among crop types and tillage systems (Baguette and Hance 1997).

The general aim of the present study was to evaluate two alternative tillage systems (CT vs. CoT) with regard to the diversity and composition of plant and Carabids (Coleoptera: Carabidae) communities in three crop types [i.e., maize, soybean, and winter cereals (incl. barley and wheat)]. We chose these taxa due to their importance as powerful indicators of sustainability in agricultural ecosystems and as crucial component for several ecological functions (e.g., control of insect pests, for Carabids, and floral resource for pollinators, for plants).

We hypothesized that the impact of CT on biodiversity and biocoenosis composition differs significantly according to crop type. More specifically, we wanted to find out whether or not there are characteristic species pools of plant and Carabids which occur predominantly on fields subject to CT but not on conventionally tilled fields (CoT). In addition, we expected to find a greater biodiversity in CT fields as compared to CoT fields. We further expected that crop types affect both species composition and diversity, with particular regard to their interaction with tillage system. Hence, this work proposes a new integrated approach to assess potential benefit of CT practices, stressing the need of combining both biodiversity and species composition analyses.

The attention has been given to the associated biodiversity, as defined above, by considering the field environment (for both flora and fauna) and the grass strips bordering the fields (flora).

\section{Materials and Methods}

\section{Study Area and Sampling Design}

The study area was the agricultural landscape of the lowlands of Friuli Venezia Giulia (Northern Italy, $45^{\circ} 51^{\prime} 24^{\prime \prime} \mathrm{N}$ $13^{\circ} 00^{\prime} 33^{\prime \prime} \mathrm{E}$ to $\left.46^{\circ} 01^{\prime} 28^{\prime \prime} \mathrm{N} 13^{\circ} 03^{\prime} 01^{\prime \prime} \mathrm{E}\right)$. Lithology is characterized by Holocene alluvial and Pleistocene fluvioglacial sediments (Martinis 1993; Carulli 2006). The regional climate is temperate with a mean annual precipitation range from 1,159 to $1,415 \mathrm{~mm}$ and a mean annual temperature of $13{ }^{\circ} \mathrm{C}$. 
During the study nine pairs of adjacent fields (CT vs. CoT) were surveyed (Table 1). The distribution of sites followed a balanced orthogonal split-plot design. Three representative sites of north Italy low plain agricultural landscape (i.e., site A, B, C) were randomly selected. Within each site, three representative crops (i.e., maize, soybean, and winter cereals-including wheat and barley) were investigated with random pairs of adjacent field managed either with CT or CoT practices. Field sizes were comparable whereas distances of field centroids never exceeded $250 \mathrm{~m}$ (Table 1). Comparison of field sizes and distances between CT and CoT did not show significant differences (linear mixed models; $P>0.05$ ), we thus assumed them to be irrelevant for the results of the experiment.

CT included all techniques characterized by non-inversion of soil for at least 5 years (Table 1). On the other hand, under CoT the seedbed was prepared by deep primary tillage with inversion of the surface layer of soil. Ploughing depths were $40 \mathrm{~cm}$ for summer crops (maize, soybean) and $30 \mathrm{~cm}$ for winter cereals. Ploughing was immediately followed by one or two tills for seedbed preparation. On average, five cropping operations per year were done under both tillage systems; herbicide applications were more frequent in fields under CT than under CoT, but still comparable (Table 1).

In each field, the soil was characterized in terms of (i) texture (i.e., \% of sand, silt, and clay), (ii) $\mathrm{pH}$, (iii) organic matter content, (iv) nitrogen, (v) carbon, and (vi) Olsen $\mathrm{P}$ content. Soil samples were collected at the end of the experiment (October 2010). In each field, 10 regularly distributed cores of the top soil $(20 \mathrm{~cm})$ were collected. On the 18 fields studied, soils were slightly acidic or neutral (Soil Survey Division Staff 1993). Even though the organic matter content tended to be slightly higher in soils subject to CT than CoT (Table 1), differences were not significant (Linear Mixed Models; $P>0.05$ ). All the other soil features were also compared without significant results (Linear Mixed Models; $P>0.05)$. The analysis of the landscape context of the fields with regard to the percentage of non-crop habitats in a 250-m-wide buffer zone around each fields, yielded no significant differences between CT and CoT fields (Linear Mixed Models; $P>0.05$, Table 1). We thus assumed that landscape variability did not have major influence on our experiment.

\section{Vegetation Relevés}

Vegetation analysis focused both on field weed (field weeds $=\mathrm{FW}$ ) and adjoining edges communities (field margin flora $=$ FMF). FMF was studied since several studies suggest major interactions between the plants inside and just outside the fields (Fried et al. 2009; Marshall and Moonen 2002).

During 2010, within each field three seasonal flora surveys (spring, summer, and autumn) were carried out.

The sampling scheme of plants consisted of 11 square plots $(1 \mathrm{~m} \times 1 \mathrm{~m})$ placed inside the field (with a cross scheme) and 5 plots of the same surface placed along the field margin, $50 \mathrm{~cm}$ far from the field border. On each plot, we recorded all the spontaneous vascular species and estimated their abundances values (percentage of cover) (Braun-Blanquet 1964). Nomenclature, life form (Raunkiaer 1934) and native or alien status followed Pignatti (1982) and Poldini et al. (2001).

\section{Sampling of Fauna}

Carabids were sampled using plastic pitfall traps $(9 \mathrm{~cm}$ in diameter and $12 \mathrm{~cm}$ deep), inserted flush with the soil surface and containing a saturated water- $\mathrm{NaCl}$ solution, added with surfactant. In each sampled site a linear transect of five pitfall traps, spaced at $2 \mathrm{~m}$ intervals, was located in the middle of the field. The five traps content was collected three times, concurrently with flora surveys (spring, summer, and autumn), 10 days after their placement. This sampling period represents the minimum period for a quick discontinuous sampling of the Carabid population at a given site (Brandmayr et al. 2005). Species nomenclature followed Vigna Taglianti (1993).

\section{Statistical Analysis}

Prior to analysis, the three seasonal pseudoreplicates were pooled, using (i) each plant taxon maximum cover value observed on a given plot, and for (ii) each Carabid taxon the sum of all the individuals collected at a given trap site. In addition, for species diversity analyses, data were further summarized within each field, using the average cover values of plot replications of each plant taxon and the sum of individuals of each Carabid taxon.

Flora and fauna taxonomic diversity were assessed by species richness $(S)$, Shannon diversity index $\left(H^{\prime}\right)$ (Shannon and Weaver 1949), and Pielou index of evenness $\left(J^{\prime}\right)$ (Pielou 1966). Linear mixed models were applied to test the main effects on diversity (i.e., $S, H^{\prime}, J^{\prime}$ ) of tillage systems (i.e., CT vs. CoT), crops, and their interaction. The random effects were included using the following hierarchical order: geographical location (i.e., site) and paired fields identifier code. The linear mixed models were applied using the "nlme" package (Pinheiro et al. 2009) in R ( R Core Team 2013). Assumptions of linear mixed model were verified using the diagnostic plots of model residuals. 


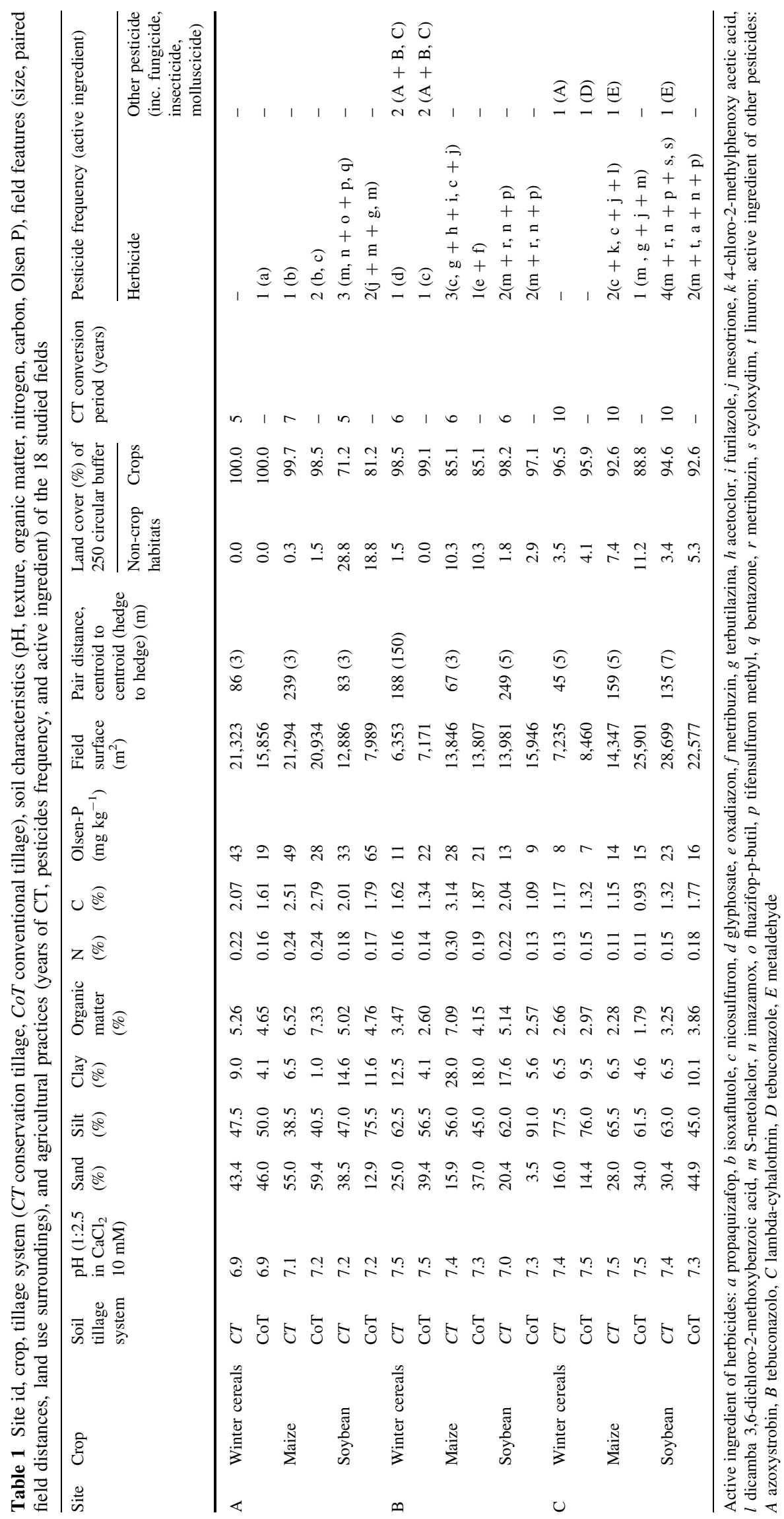


In order to fulfill a comprehensive data exploration on Carabids communities, we also conducted a comparison of Carabid functional groups (i.e., diet, wing type). No significant differences between tillage systems were found for both diet (i.e., zoophagous, polyphagous, and phytophagous) and wings (i.e., macropterous, brachypterous, and dimorphic) groups (LMM; $P>0.05$ ).

Species composition of both plant (i.e., FW, FMF) and fauna (Carabid) communities were investigated by Canonical (constrained) correspondence analysis (CCA). We used CCA because the gradient lengths, calculated preliminarily with detrended correspondence analysis (DCA), exceeded 2.5 SD units (i.e., 5.2 for FW, 4.8 for FMF, and 4.4 for Carabids) (ter Braak 1986; Legendre and Legendre 1998; Borcard et al. 2011). CCA were carried out using both species matrix and environmental factors matrix. Species matrix included all the summarized (i.e., without seasonal variability) plots and all the taxa occurring in all the plots with a frequency higher than $5 \%$; this allowed to minimize the influence of occasional species. The replicates within each field (i.e., 11 for FW, 5 for FMF, and 5 for Carabids) were included in order to consider each field variability. Environmental factor matrices were distinguished for plants and fauna analysis and all the considered factors were previously normalized. Plants environmental factors matrix encompassed dummy variables, such the conservation management (i.e., CT) and crop (i.e., maize, soybean and winter cereals), and selected soil variables (i.e., organic matter, $\mathrm{pH}$, phosphorus) (Table 1). Soil variables were selected as sensitive indicators of soil differences between the two farming systems, which could affect the pattern of FW. Carabids environmental factors matrix encompassed management and crops, as dummy variables, and species number of principal life form groups of FW (i.e., therophyte, hemicryptophyte, geophyte). Plant life forms were included in order to point out relationships between plant communities and Carabid communities. Species abundances were previously transformed by square root transformation to avoid dominant species overrating (Legendre and Legendre 1998; Wildi 2013). All constraints of CCA were selected using forward selection method. CCA were performed by package "vegan" (Oksanen et al. 2012) in R (R Core Team 2013). Significances of CCA constraints were tested with the "anova" CCA permutation test function (999 permutations) of "vegan" package.

\section{Results}

\section{Plant and Carabid Diversity}

During the study a total of 136 plant taxa (including species, subspecies) were recorded, of which 83 were found inside (FW) and 122 just outside the fields (FMF).
Management (CT vs. CoT), crop types, and their interaction effects on taxonomic diversity (i.e., $S, H^{\prime}, J^{\prime}$ ) were analyzed by separated linear mixed models for both FW and FMF (Table 2). Significant differences were found only for $S$ index in FW for tillage system and tillage system-crops interaction. The number of FW taxa was greater under CoT $(S=17.0)$ than under CT $(S=14.0)$. This difference was primarily due to values observed in the pairs of fields with winter cereals $(T$ value $=3.633$, $P$ value $=0.01)$. No significant differences were observed with regard to Shannon diversity $\left(H^{\prime}\right)$ and evenness $\left(J^{\prime}\right)$.

Species diversity $\left(S, H^{\prime}\right)$ and evenness $\left(J^{\prime}\right)$ of the flora along the outer edges of the fields (FMF), by contrast, was the same under all combinations of tillage system and crop.

In both the agricultural management systems the same number of Carabid species (45 species) was collected. Fauna species diversities indices (Table 2) showed a significant difference of $S$ within the crop level. The winter cereals $(S=17.3)$ showed a significant higher number of species than summer crops (i.e., maize, $S=10.8$, and soybean, $S=9.5$ ). $H^{\prime}$ indices showed a similar trend while $J^{\prime}$ highlighted a lower variability within both crops and management factors.

\section{Species Composition of Plant and Carabid}

Communities

Constrained variables of CCA of plant communities inside the fields (FW) explained $18 \%(P<0.01)$ of the total inertia. The distribution of crops under $\mathrm{CT}$ and CoT along the first two axes (6\% of total inertia) showed the two following trends (Fig. 1a). Along the first axis (CCA1, $31.6 \%$ of proportion explained) the plots are mainly distributed according to soil $\mathrm{pH}$ and crop type. The second axis (CCA2, $23.9 \%$ ) better explained the differences in terms of plant composition due to CT system and nutrients (i.e., organic matter and soil phosphorus). Regarding plant species, CT system showed higher species scores for Sorghum halepense, Digitaria sanguinalis, Amaranthus retroflexus, and Cardamine hirsuta, whereas CoT showed higher scores for Geranium dissectum, Cerastium brachypetalum, and Convolvulus arvensis.

CCA on FMF data (Fig. 1b) showed a clear separation of $\mathrm{CT}$ versus CoT along the first two axes. The constrained variables explained $19.9 \%(P<0.01)$ of the total inertia, $6.1 \%$ of which was explained by the first two axes. Along the first axis (CCA1; $27.3 \%$ of proportion explained) the following trends were observed (i) increase in soil nutrients (i.e., organic matter and soil phosphorus), (ii) decrease in $\mathrm{pH}$, and (iii) change of tillage system (CT vs. CoT). Likewise, on the second axis it was possible to recognize the effect of tillage system associated with soil $\mathrm{P}$, whereas the impact of crop type seemed to be negligible. According 
Table 2 Outcomes of linear mixed models testing the effects of crop type (i.e., maize, soybean, winter cereals) tillage system (conservation tillage vs. conventional tillage) and their interaction on Carabids, plant fields (FW), and plant margins (FMF) diversity in the 18 studied fields

\begin{tabular}{|c|c|c|c|c|c|c|c|}
\hline & \multirow[t]{2}{*}{ d.f. } & \multicolumn{2}{|c|}{ CARABIDS } & \multicolumn{2}{|l|}{ FW } & \multicolumn{2}{|l|}{ FMF } \\
\hline & & $F$ value & $P$ value & $F$ value & $P$ value & $F$ value & $P$ value \\
\hline \multicolumn{8}{|l|}{ S } \\
\hline (Intercept) & 1,6 & 124.88 & $<0.0001$ & 64.69 & 0.000 & 223.75 & $<0.0001$ \\
\hline Crop & 2,4 & 10.48 & 0.026 & 4.52 & 0.094 & 1.32 & 0.364 \\
\hline Soil management & 1,6 & 0.35 & 0.574 & 6.15 & 0.048 & 0.19 & 0.680 \\
\hline Crop:soil manag. & 2,6 & 3.19 & 0.114 & 6.36 & 0.033 & 0.49 & 0.638 \\
\hline \multicolumn{8}{|l|}{$\mathrm{H}^{\prime}$} \\
\hline (Intercept) & 1,6 & 73.88 & 0.000 & 207.27 & $<0.0001$ & 439.07 & $<0.0001$ \\
\hline Crop & 2,4 & 0.00 & 0.997 & 1.58 & 0.313 & 0.78 & 0.517 \\
\hline Soil management & 1,6 & 2.10 & 0.198 & 1.29 & 0.300 & 0.04 & 0.842 \\
\hline Crop:soil manag. & 2,6 & 0.51 & 0.626 & 0.19 & 0.831 & 0.21 & 0.817 \\
\hline \multicolumn{8}{|l|}{$\mathrm{J}^{\prime}$} \\
\hline (Intercept) & 1,6 & 161.87 & $<0.0001$ & 371.83 & $<0.0001$ & 797.03 & $<0.0001$ \\
\hline Crop & 2,4 & 1.30 & 0.367 & 0.38 & 0.705 & 1.21 & 0.388 \\
\hline Soil management & 1,6 & 2.12 & 0.195 & 1.37 & 0.286 & 0.01 & 0.946 \\
\hline Crop:soil manag. & 2,6 & 0.17 & 0.848 & 0.23 & 0.798 & 0.87 & 0.468 \\
\hline
\end{tabular}

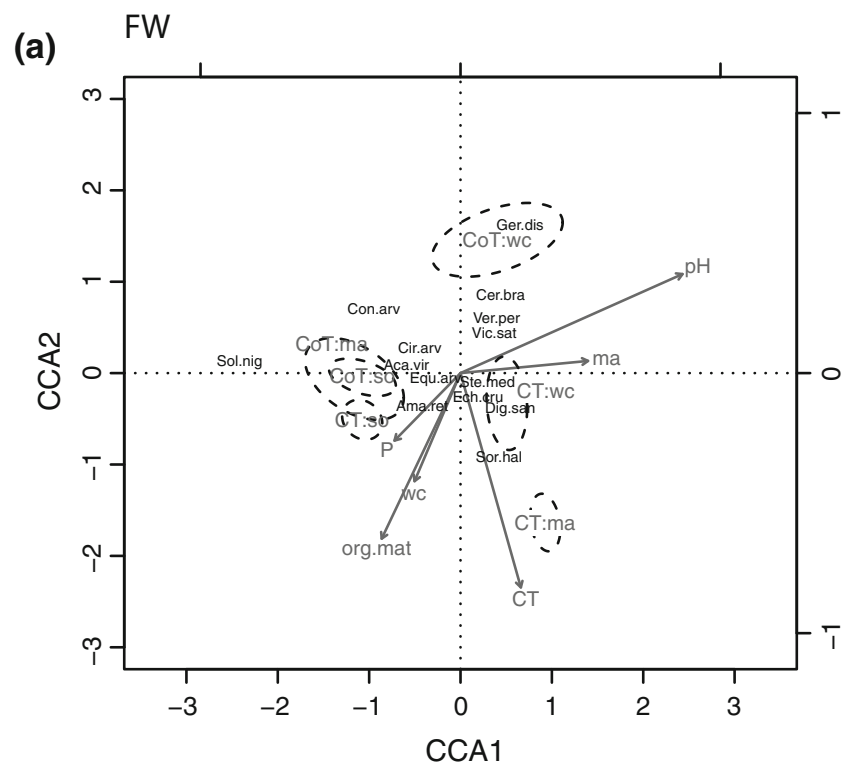

Fig. 1 Ordination triplot depicting the first two axes (i.e., CCA1 and CCA2) of Canonical correspondence analysis (CCA) of a field flora weed (FW) plots and $\mathbf{b}$ field margin flora (FMF) plots. Centroids of crops and tillage system combination (i.e., $C T$ conservation tillage systems, CoT conventional system of soil management, $m a$ maize, so soybean, $w c$ winter cereals) and their standard error of the average of scores (dashed elliptic lines with $95 \%$ confidence limit) are showed. A selection of species was plotted according to species scores and further abundance priority selection (Alo.myo, Alopecurus myosuroides; Aca.vir, Acalypha virginica; Ama.ret, Amaranthus retroflexus subsp. retroflexus; Ani.ste, Anisantha sterilis; Car.acu, Carex acutiformis; Cer.bra, Cerastium brachypetalum subsp. brachypetalum; Cir.arv, Cirsium arvense; Con.arv, Convolvulus arvensis; Cyn.dac, Cynodon dactylon; Dig.san, Digitaria sanguinalis; Ech.cru, Echinochloa crus-galli subsp. crus-galli; Ele.ind, Eleusine indica subsp.

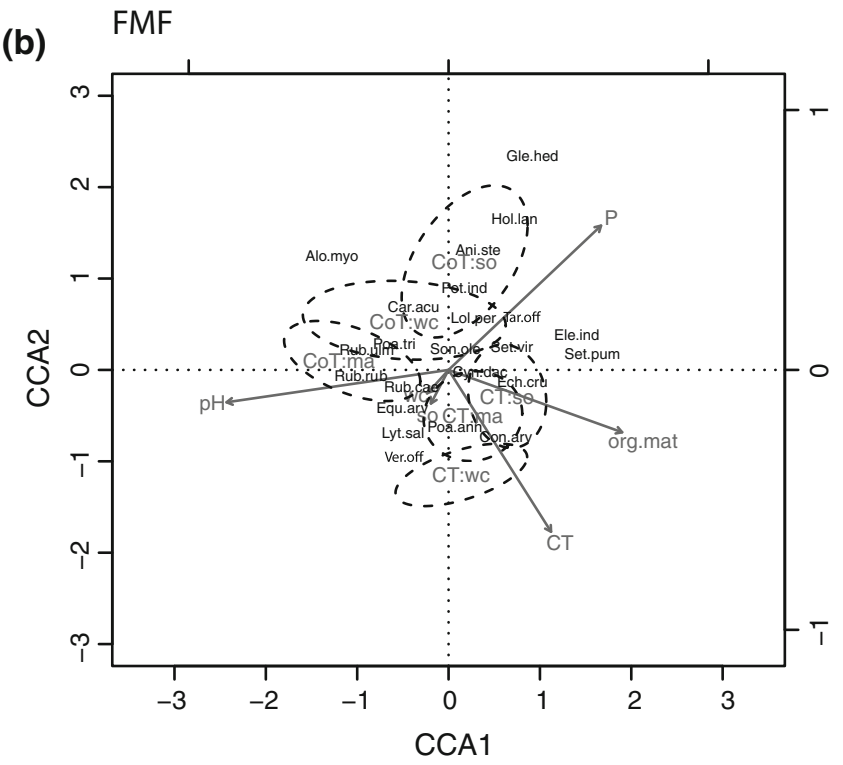

indica; Equ.arv, Equisetum arvense; Ger.dis, Geranium dissectum; Gle.hed, Glechoma hederacea; Hol.lan, Holcus lanatus; Lol.per, Lolium perenne; Lyt.sal, Lythrum salicaria; Poa.ann, Poa annua subsp. annua; Poa.tri, Poa trivialis; Pot.ind, Potentilla indica; Rub.cae, Rubus caesius; Rub.rub, Rubus subgen. Rubus sect. Rubus; Rub.ulm, Rubus ulmifolius; Set.pum, Setaria pumila; Set.vir, Setaria viridis; Sol.nig, Solanum nigrum; Son.ole, Sonchus oleraceus; Sor.hal, Sorghum halepense; Ste.med, Stellarietea mediae subsp. media; Tar.off, Taraxacum sect.Taraxacum; Ver.off, Verbena officinalis; Ver.per, Veronica persica; Vic.sat, Vicia sativa). Main arrows represent the selected constrained variables ( $C T$ conservation tillage dummy variable, ma maize crop dummy variable, so soybean crop dummy, $w c$ winter cereals dummy variable, org.mat soil organic matter, $p H$ soil $\mathrm{pH}, P$ soil phosphorus content) 


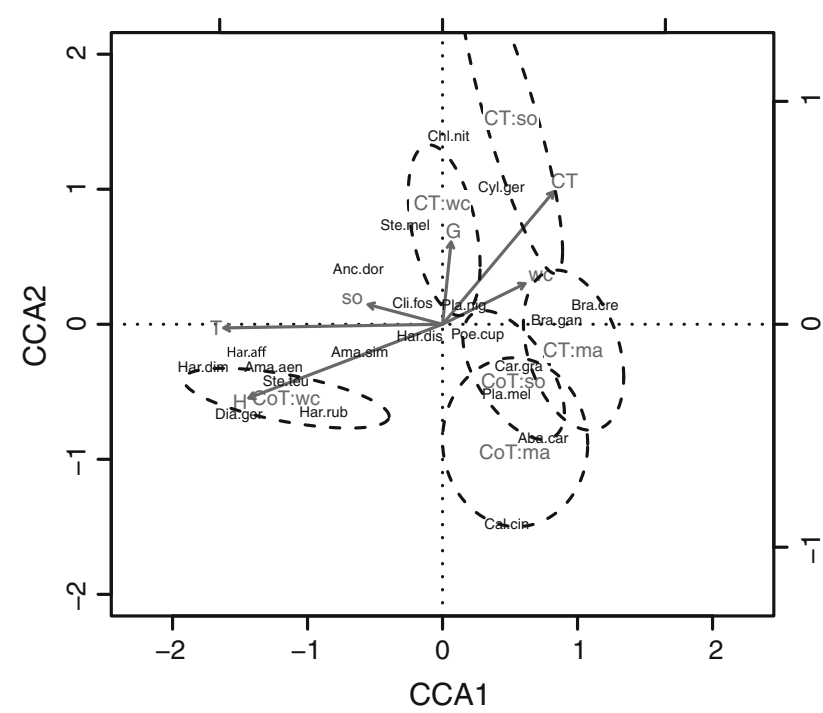

Fig. 2 Ordination triplot depicting the first two axes (i.e., CCA1 and CCA2) of Canonical correspondence analysis (CCA) of carabids. Centroids of crops and tillage system combination (i.e., CT conservation tillage systems, CoT conventional system of soil management; $m a$ maize, so soybean, $w c$ winter cereals) and their standard error of the average of scores (dashed elliptic lines with $95 \%$ confidence limit) are showed. A selection of species was plotted according to species scores and further abundance priority selection (Aba.car, Abax carinatus; Ama.aen, Amara aenea; Anc.dor, Anchomenus dorsalis; Bra.cre, Brachynus crepitans; Bra.gan, Brachynus ganglbaueri; Cal.cin, Calathus cinctus; Car.gra, Carabus granulatus; Chl.nit, Chlaeniellus nitidulus; Cli.fos, Clivina fossor; Cyl.ger, Cylindera germanica; Dia.ger, Diachromus germanus; Har.aff, Harpalus affinis; Har.dim, Harpalus dimidiatus; Har.dis, Harpalus distinguendus; Har.rub, Harpalus rubripes; Pla.mel, Platysma melanarium; Pla.nig, Platysma nigrum; Poe.cup, Poecilus cupreus; Ste.mel, Steropus melas; Ste.teu, Stenolophus teutonus). Main arrows represent the selected constrained variables ( $C T$ conservation tillage dummy variable; $w c$ winter cereals dummy variable; so soybean crop dummy variable; $G$ geophytes; $H$ hemicryptophytes; $T$ therophytes)

to species scores it was possible to identify a set of taxa closely associated with CT. Species as Setaria pumila, Eleusine indica, (CCA1), Verbena officinalis, C. arvensis, and Polygonum aviculare (CCA2) reached their highest occurrence in plots along the edges of fields subject to CT. On the other hand Alopecurus myosuroides, Equisetum telmateia, V. officinalis (CCA1), Holcus lanatus, Anisantha sterilis, and Glechoma hederacea (CCA2) had their maximum along the margins of fields subject to CoT.

Constrained variables of CCA for Carabids communities (Fig. 2) explained $23.7 \%$ of the total inertia. The first two axes $(14.9 \%$ of total inertia; $P<0.01)$ showed a separation of site centroids mainly according to crop types and plant life forms (i.e., number of $\mathrm{T}$ and $\mathrm{H}$ ) through CCA1 (41.2\% of proportion explained) and tillage system (CT vs. CoT) associated with number of geophytes (G) along CCA2 $(21.8 \%$ of proportion explained). The Carabid species Chlaeniellus nitidulus, Cylindera germanica, and
Steropus melas were primarily associated to fields subject to CT, whereas, CoT was characterized by the presence of Calathus cinctus, Abax carinatus, Diachromus germanus. The species Harpalus dimidiatus, Harpalus rubripes, and Harpalus affinis were associated with winter cereals, also rich in therophyte and hemicriptophyte plants. Summer crops (i.e., maize and soybean) showed high frequency of Brachynus ganglbaueri, Brachynus crepitans, and A. carinatus.

\section{Discussion and Conclusions}

Except for the number of plant species $(S)$ inside the fields $(\mathrm{FW})$, the two tillage systems did not show significant differences with regard to their floristic or faunistic species diversity. These results are in accordance with other studies on the effects of CT on biological diversity. Based on 23-years crop rotation experiment in Mediterranean drylands, Hernandez Plaza et al. (2011) concluded that CT did not significantly affect weed diversity. Likewise, Shrestha et al. (2002) did not find differences in weed densities and species composition between no-tillage and CoT. Murphy et al. (2006), on the other hand, found CT (i) to produce the greatest diversity of weeds and (ii) to affect weed density in different crop rotation schemes (continuous corn, cornsoybean, corn-soybean-winter wheat).

Regarding the literature on the impact of tillage systems on biodiversity, contrasting results were not only reported on plants but also on Carabids. Hatten et al. (2007), for instance, concluded that species richness and biological diversity of Carabids were generally greater under no-tillage than under CoT. However, there are also many studies suggesting that diversity and species richness of Carabids are not affected by tillage system, emphasizing the need to focus the attention on ecological features and functional groups inside the Carabids (Belaoussoff et al. 2003; Clough et al. 2007; Gobbi and Fontaneto 2008).

The research results pointed out different pools of species for CT and CoT soil management, for both Carabid and plant indicators. On the fields with winter cereals, differences in species composition were, indeed, significantly greater than in fields with maize and soybean, for both the plants and Carabids inside the fields (FW) (Figs. 1a, 2). This is completely in line with the traditional phytosociological subdivision of annual crops weed communities (Stellarietea mediae) into weed communities of winter crop (Centaureetalia cyani) and summer crops (Chenopodietalia albi), respectively (Aeschimann et al. 2004). Regarding the effect of crop type on Carabids communities, Eyre et al. (2013) found significant differences between fields with cereals and vegetables, respectively, and the same was true for the study of Östman et al. 
(2003) comparing cereal fields and grasslands. In general, ground cover seems to foster the abundance of Carabids (Hummel et al. 2002).

In the present study, fields subject to CoT were characterized by annual plant species (i.e., therophytes), often representing typical species of the segetal flora of arable fields (i.e., archeophytes). Fields subject to CT, on the contrary, were characterized by annual and perennial weeds (i.e., therophytes and geophytes, respectively), which are nutrient demanding. According to the literature these nutrient-demanding species are usually associated with soils that have a good structure and a comparatively high content of organic matter (Holland 2004; Trewavas 2004). Many authors confirmed that the soil structure under CT would be better than under CoT (Hermawan and Cameron 1993; Pagliai et al. 2004), even though no significant differences in organic matter content between the two tillage systems were found here.

The Carabids species found in the fields subject to CT were all closely related to the perennial geophytes, indicating that they depended on more stable plant communities than the Carabids species found for the fields under CoT. According to the literature, geophytes are generally considered as indicators for both better edaphic conditions and CT (Moyer et al. 1994; Zanin et al. 1997). Perennial weed species with rhizomes, tubercles, or bulbs are well adapted to slight mechanical soil perturbations (Fried et al. 2009; Nascimbene et al. 2012).

Finally, concerning the field margins, the composition of the vegetation differed significantly between the two studied tillage systems. Associated with CT was mostly annual and perennial weeds such as, for instance, S. pumila, E. indica, and $P$. aviculare. The plant species found along the outer edges of the fields subject to CoT, by contrast, were $H$. lanatus, $G$. hederacea, and V. officinalis, i.e., species typically found in Molinio-Arrhenatheretea elatioris-meadows, which are fairly rich in nutrients and moderately well supplied with water. Management treatments carried out on the fields such as ploughing, tilling, pest control, etc. will, of course, also affect plants and animals at the outer edge of the fields and therefore the composition of the boundary communities (Hald 1999; Marshall and Moonen 2002; Hovd and Skogen 2005; Aavik and Liira 2010). In the present study, therefore, species like S. halepense and Setaria viridis were not only frequent inside the fields subject to CoT but also along their outer edges.

In conclusion, our findings indicate that CT did not significantly affect species diversity of plants or Carabids. However, species composition did show a clear relation with more stable habitat conditions under CT than under CoT, as indicated, for instance, by characteristics species of plants and Carabids. The present study clearly revealed that biodiversity indices are not sufficient for assessing and characterizing the environmental quality of agro-ecosystems under different tillage systems. In contrast, plants and Carabids species composition proved to be valuable indicators of the ecological conditions under different tillage system.

Acknowledgments The authors thank the farmers involved for granting free access to their fields and Prof. Pietro Brandmayr for advice on Carabids analysis. The research was funded by the Friuli Venezia Giulia region (MULTIFARM Project, L.R. 26/05 art. 17).

\section{References}

Aavik T, Liira J (2010) Quantifying the effect of organic farming, field boundary type and landscape structure on the vegetation of field boundaries. Agric Ecosyst Environ 135(3):178-186

Aeschimann D, Lauber K, Moser DM, Theurillat JP (2004) Flora Alpina. Zanichelli, Bologna

Albrecht H (2003) Suitability of arable weeds as indicator organisms to evaluate species conservation effects of management in agricultural ecosystems. Agric Ecosyst Environ 98:201-211

Altieri MA, Nicholls CI (2004) Biodiversity and pest management in agroecosystems. Haworth Press, New York

Andersson TN, Milberg P (1998) Weed flora and the relative importance of site, crop, crop rotation, and nitrogen. Weed Sci 46:30-38

Baguette M, Hance T (1997) Carabid beetles and agricultural practices: influence of soil ploughing. Biol Agric Hortic 15(1-4): 185-190

Barney RJ, Pass BC (1986) Ground beetle (Coleoptera: Carabidae) populations in Kentucky alfalfa and influence of tillage. J Econ Entomol 79:511-517

Belaoussoff S, Kevan PG, Murphy S, Swanton C (2003) Assessing tillage disturbance on assemblages of ground beetles (Coleoptera: Carabidae) by using a range of ecological indices. Biodivers Conserv 12:851-882

Booij K (1994) Diversity patterns in carabid assemblages in relation to crops and farming systems. In: Desender K, Dufrêne M, Loreau M, Luff ML, Maelfait J-P (eds) Carabid beetles: ecology and evolution, series entomologica, vol 51. Springer, Netherlands, pp 425-431

Borcard D, Gillet F, Legendre P (2011) Numerical ecology with R. Springer, New York

Brandmayr P, Zetto T, Pizzolotto R (2005) I Coleotteri Carabidi per la valutazione ambientale e la conservazione della biodiversità. APAT, Manuale operativo 34/2005. ISBN 88-448-0152-3

Braun-Blanquet J (1964) Pflanzensoziologie. Grundzuge der Vegetationskunde. Springer, Wien

Carcamo HA (1995) Effect of tillage on ground beetles (Coleoptera: Carabidae): a farm-scale study in central Alberta. Can Entomol 127:631-639

Carcamo HA, Spence JR (1994) Crop type effects on the activity and distribution of ground beetles (Coleoptera: Carabidae). Environ Entomol 23(3):684-692

Carulli GB (2006) Carta Geologica del Friuli Venezia Giulia, scala 1:150.000. S.EL.CA, Firenze

Clough Y, Holzschuh A, Gabriel D, Purtauf T, Kleijn D, Kruess A, Steffan-Dewenter I, Tscharntke T (2007) Alpha and beta diversity of arthropods and plants in organically and conventionally managed wheat fields. J Appl Ecol 44:804-812

Cole LJ, McCracken DI, Downie IS, Dennis P, Foster GN, Waterhouse T, Murphy KJ, Griffin AL, Kennedy MP (2005) Comparing the effects of farming practices on ground beetle 
(Coleoptera: Carabidae) and spider (Araneae) assemblages of Scottish farmland. Biodivers Conserv 14:441-460

Conant RT, Easter M, Paustian K, Swan A, Williams S (2007) Impacts of periodic tillage on soil C stocks: a synthesis. Soil Till Res 95:1-10

Dorado J, López-Fando C (2006) The effect of tillage system and use of a paraplow on weed flora in a semiarid soil from central Spain. Weed Res 46(5):424-431

Eyre MD, Luff ML, Leifert C (2013) Crop, field boundary, productivity and disturbance influences on ground beetles (Coleoptera, Carabidae) in the agroecosystem. Agric Ecosyst Environ 165:60-67

Field RH, Benke S, Badonyi K, Bradbury RB (2007) Influence of conservation tillage on winter bird use of arable fields in Hungary. Agric Ecosyst Environ 120:399-404

French BW, Elliott NC, Berbereti RC (1998) Reverting conservation reserve program lands to wheat and livestock production: effects on ground beetle (Coleoptera: Carabidae) assemblages. Environ Entomol 27(6):1323-1335

Fried G, Norton LR, Reboud X (2008) Environmental and management factors determining weed species composition and diversity in France. Agric Ecosyst Environ 128(1-2):68-76

Fried G, Petit S, Dessaint F, Reboud X (2009) Arable weed decline in Northern France: crop edges as refugia for weed conservation? Biol Conserv 142:238-243

Gobbi M, Fontaneto D (2008) Biodiversity of ground beetles (Coleoptera: Carabidae) in different habitats of the Italian Po lowland. Agric Ecosyst Environ 127(3-4):273-276

Hald AB (1999) Weed vegetation (wild flora) of long established organic versus conventional cereal fields in Denmark. Ann Appl Biol 134(3):307-314

Hatten TD, Bosque-Pérez NA, Labonte JR, Guy SO, Eigenbrode SD (2007) Effects of tillage on the activity density and biological diversity of Carabid beetles in spring and winter crops. Environ Entomol 36(2):356-368

Hermawan B, Cameron KC (1993) Structural changes in a silt loam under long-term conventional or minimum tillage. Soil Till Res 26(2):139-150

Hernandez Plaza E, Kozak M, Navarrete L, Gonzalez-Andujara JL (2011) Tillage system did not affect weed diversity in a 23-year experiment in Mediterranean dryland. Agric Ecosyst Environ 140:102-105

Holland JM (2004) The environmental consequences of adopting conservation tillage in Europe: reviewing the evidence. Agric Ecosyst Environ 103:1-25

Holland JM, Luff ML (2000) The effects of agricultural practices on Carabidae in temperate agroecosystems. Integr Pest Manag Rev 5:109-129

House GJ, Stinner BR (1983) Arthropods in no-tillage soybean agroecosystems: community composition and ecosystem interactions. Environ Manag 7(1):23-28

Hovd H, Skogen A (2005) Plant species in arable field margins and road verges of central Norway. Agric Ecosyst Environ 110(3-4):257-265

Hummel LR, Walgenbach JF, Hoyt GD, Kennedy GG (2002) Effects of vegetable production system on epigeal arthropod populations. Agric Ecosyst Environ 93:177-188

Kromp B (1999) Carabid beetles in sustainable agriculture: a review on pest control efficacy, cultivation impacts and enhancement. Agric Ecosyst Environ 74(1-3):187-228

Lahmar R (2010) Adoption of conservation agriculture in Europe lessons of the KASSA project. Land Use Policy 27:4-10

Legendre P, Legendre L (1998) Numerical Ecology, Second English edn. Elsevier, Amsterdam

Marshall EJP, Moonen AC (2002) Field margins in northern Europe: their functions and interactions with agriculture. Agric Ecosyst Environ 89(1-2):5-21
Martinis B (1993) Storia geologica del Friuli. La Nuova Base Ed., Udine

Mas MT, Verdú AMC (2003) Tillage system effects on weed communities in a 4-year crop rotation under Mediterranean dryland conditions. Soil Till Res 74(1):15-24

Moyer JR, Roman ES, Lindwall CW, Blackshaw RE (1994) Weed management in conservation tillage systems for wheat production in North and South-America. Crop Prot 13:243-259

Mueller DH, Daniel TC, Wendt RC (1981) Conservation tillage: best management practice for nonpoint runoff. Environ Manag 5(1):33-53

Murphy DS, Clements DR, Belaoussoff S, Kevan PG, Swanton CG (2006) Promotion of weed species diversity and reduction of weed seedbanks with conservation tillage and crop rotation. Weed Sci 54(1):69-77

Nascimbene J, Marini L, Paoletti MG (2012) Organic farming benefits local plant diversity in vineyard farms located in intensive agricultural landscapes. Environ Manag 49(5): 1054-1060

Oksanen J, Blanchet FG, Kindt R, Legendre P, Minchin PR, O'Hara RB, Simpson GL, Solymos P, Stevens MHH, Wagner H (2012). vegan: Community Ecology Package. $\mathrm{R}$ package version 2.0-4

Östman O, Ekbom B, Bengtsson J (2003) Yield increase attributable to aphid predation by ground-living polyphagous natural enemies in spring barley in Sweden. Ecol Econ 45:149-158

Pagliai M, Vignozzi N, Pellegrini S (2004) Soil structure and the effect of management practices. Soil Till Res 79(2):131-143

Pielou EC (1966) The measurement of diversity in different types of biological collections. J Theor Biol 13:131-144

Pignatti S (1982) Flora d'Italia. Edagricole, Bologna

Pinheiro J, Bates D, DebRoy S, Sarkar D, The R Core Team (2009) nlme: linear and nonlinear mixed effects models. $\mathrm{R}$ package version 3

Pisante M (2007) Agricoltura Blu. La via italiana dell'agricoltura conservativa. Principi, tecnologie e metodi per una produzione sostenibile. Edagricole, Bologna

Poldini L, Oriolo G, Vidali M (2001) Vascular flora of Friuli-Venezia Giulia. An annotated catalogue and synonimic index. Studia Geobot 21:3-277

Raunkiær C (1934) The life forms of plants and statistical plant geography. Oxford University Press, Oxford

Shannon C, Weaver W (1949) The mathematical theory of communication. University of Illinois Press, Urbana

Shearin AF, Reberg-Horton SC, Gallandt ER (2007) Direct effects of tillage on the activity density of ground beetle (Coleoptera: Carabidae) weed seed predators. Environ Entomol 36(5):1140-1146

Shrestha A, Knezevic SZ, Roy RC, Ball-Coelho BR, Swanton CJ (2002) Effect of tillage, cover crop and crop rotation on the composition of weed flora in a sandy soil. Weed Res 42:76-87

Soil Survey Division Staff (1993) Soil survey manual. Soil Conservation Service. U.S. Department of Agriculture Handbook, vol. 18. http://soils.usda.gov/technical/manual. Accessed 1 Mar 2012

Streit B, Rieger SB, Stamp P, Richner W (2002) The effect of tillage intensity and time of herbicide application on weed communities and populations in maize in central Europe. Agric Ecosyst Environ 92:211-224

R Core Team (2013) R: A language and environment for statistical computing. R Foundation for Statistical Computing, Vienna, Austria

ter Braak CJF (1986) Canonical correspondence analysis: a new eigenvector technique for multivariate direct gradient analysis in ecology. Ecology 67:1167-1179

Trewavas A (2004) A critical assessment of organic farming-and-food assertions with particular respect to the UK and the potential environmental benefits of no-till agriculture. Crop Prot 23(9):757-781 
Vandermeer J, Perfecto I (1995) Breakfast of biodiversity: the truth about rainforest destruction. Food First Books, Oakland

Vigna Taglianti A (1993) Coleoptera Archostemata Adephaga 1 (Carabidae). In: Minelli A, Ruffo S, La Posta S (eds) Checklist delle specie della fauna italiana, vol 44. Calderini, Bologna

Waldhardt R, Simmering D, Albrecht H (2003) Floristic diversity at the habitat scale in agricultural landscapes of Central Europesummary, conclusions and perspectives. Agric Ecosyst Environ 98(1-3):79-85

Wildi O (2013) Data analysis in vegetation ecology, 2nd edn. WileyBlackwell, Chichester

Zanin G, Otto S, Riello L, Borin M (1997) Ecological interpretation of weed flora dynamics under different tillage systems. Agric Ecosyst Environ 66:177-188
Zentner RP, Lafond GP, Derksenc DA, Nagyd CN, Walla DD, Mayb WE (2004) Effects of tillage method and crop rotation on nonrenewable energy use efficiency for a thin Black Chernozem in the Canadian Prairies. Soil Till Res 77:2125-2136

Zentner RP, Basnyat P, Brandt SA, Thomas AG, Ulrich D, Campbell CA, Nagye CN, Frickf B, Lemkec R, Malhig SS, Fernandez MR (2011) Effects of input management and crop diversity on nonrenewable energy use efficiency of cropping systems in the Canadian Prairie. Eur J Agron 3:113-123 